Published in final edited form as:

Psychoneuroendocrinology. 2019 April ; 102: 139-148. doi:10.1016/j.psyneuen.2018.12.006.

\title{
Chronic stress exposure and daily stress appraisals relate to biological aging marker p16iNK4a
}

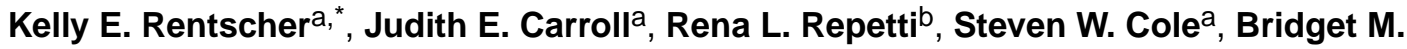 \\ Reynolds $^{c}$, and Theodore F. Robles ${ }^{a, b}$ \\ ${ }^{a}$ Cousins Center for Psychoneuroimmunology, Semel Institute for Neuroscience \& Human \\ Behavior, University of California, Los Angeles, 300 Medical Plaza, Los Angeles, CA 90095, USA \\ bDepartment of Psychology, University of California, Los Angeles, 502 Portola Plaza, Los \\ Angeles, CA 90095, USA \\ 'National Center for Health Statistics, Centers for Disease Control and Prevention, 3311 Toledo \\ Road, Hyattsville, MD 20782, USA
}

\begin{abstract}
Previous research has linked exposure to adverse social conditions with DNA damage and accelerated telomere shortening, raising the possibility that chronic stress may impact biological aging pathways, ultimately increasing risk for age-related diseases. Less clear, however, is whether these stress-related effects extend to additional hallmarks of biological aging, including cellular senescence, a stable state of cell cycle arrest. The present study aimed to investigate associations between psychosocial stress and two markers of cellular aging-leukocyte telomere length (LTL) and cellular senescence signal p16 ${ }^{\mathrm{INK} 4 \mathrm{a}}$. Seventy-three adults $\left(M_{\mathrm{age}}=43.0, S D=7.2 ; 55 \%\right.$ female) with children between $8-13$ years of age completed interview-based and questionnaire measures of their exposures to and experiences of stress, as well as daily reports of stress appraisals over an 8-week diary period. Blood samples were used to assess markers of cellular aging: LTL and gene expression of senescent cell signal p16 ${ }^{\mathrm{INK} 4 \mathrm{a}}(C D K N 2 A)$. Random effects models covarying for age, sex, ethnicity/race, and BMI revealed that participants with greater chronic stress exposure over the previous 6 months $(b=0.011, p=.04)$, perceived stress $(b=$ $0.020, p<.001)$, and accumulated daily stress appraisals over the 8-week period $(b=0.013, p=$.
\end{abstract}

\footnotetext{
*Corresponding author: Kelly E. Rentscher, Ph.D., Cousins Center for Psychoneuroimmunology, UCLA Semel Institute for Neuroscience and Human Behavior, 300 Medical Plaza, Suite 3156, Los Angeles, CA 90095-7076, Phone: +13108256834, krentscher@ucla.edu.

Contributions:

All authors have made substantial contributions to and have approved the final version of this manuscript. Specifically, the original study was conceived and designed by Rena L. Repetti, and Theodore F. Robles. Data were acquired by Rena L. Repetti, Theodore F. Robles, Bridget M. Reynolds, and Judith E. Carroll. Hypotheses regarding cellular senescence were generated and data were analyzed by Kelly E. Rentscher, Judith E. Carroll, Steven W. Cole and Theodore F. Robles. The manuscript was drafted or revised critically for intellectual content by Kelly E. Rentscher, Judith E. Carroll, Theodore F. Robles. Rena L. Repetti, and Steven W. Cole.

Publisher's Disclaimer: This is a PDF file of an unedited manuscript that has been accepted for publication. As a service to our customers we are providing this early version of the manuscript. The manuscript will undergo copyediting, typesetting, and review of the resulting proof before it is published in its final citable form. Please note that during the production process errors may be discovered which could affect the content, and all legal disclaimers that apply to the journal pertain.

Declarations of Interest:

None.

Conflict of Interest

None
} 
02) showed increased $\mathrm{p} 16^{\mathrm{INK} 4 \mathrm{a}}$. No significant associations with LTL were found. These findings extend previous work on the impact of stress on biological aging by linking chronic stress exposure and daily stressful experiences to an accumulation of senescent cells. Findings also support the hypothesis that chronic stress is associated with accelerated aging by inducing cellular senescence, a common correlate of age-related diseases.

\section{Keywords}

stress; daily diary; biological aging; cellular senescence; telomere length; gene expression

\section{Introduction}

An emergent literature suggests that exposure to adverse social conditions is associated with accelerated biological aging, offering one mechanism through which adversity may increase risk for age-related diseases, including diabetes, atherosclerosis, neurodegeneration, and cancer. Chronic stress, via prolonged or repeated activation of the sympathoadrenal system, is thought to increase disease risk through its cumulative impact on key biological aging pathways (Epel, 2009; Robles and Carroll, 2011; Shalev et al., 2014). Most well established is the connection between stress and inflammation, as the sympathoadrenal system directly regulates cellular inflammatory signaling, which has been proposed as a key driver of biological aging (Franceschi and Campisi, 2014; Irwin and Cole, 2011; Marsland et al., 2017). Other key pathways, although less well characterized, include elevated DNA damage (Forlenza et al., 2000) and shortened telomere length (Puterman and Epel, 2012). Despite this growing literature, it remains unclear whether these stress-related effects extend to other hallmarks of biological aging such as cellular senescence.

As one of the more extensively studied markers of biological aging, leukocyte telomere length (LTL) is thought to indicate faster aging and is associated with increased risk for morbidity and mortality(Epel and Prather, 2018). A sizeable literature links various forms of chronic stress exposure to shorter LTL, including childhood adversity (Kananen et al., 2010; Schaakxs et al., 2016), low socioeconomic status and neighborhood quality (Cherkas et al., 2006; Park et al., 2015), and caregiving (Damjanovic et al., 2007; Epel et al., 2004).

Prospective associations have also been observed, with the occurrence of major life stressors over 1 year predicting greater telomere shortening (Puterman et al., 2015). Other investigations have focused on psychological responses to stressful events rather than event exposure (Harkness and Monroe, 2016). Several studies link appraisals of work-related exhaustion (Ahola et al., 2012) and perceived stress (Epel et al., 2004; Mathur et al., 2016) to shorter LTL; however, others have not observed such associations (Glass et al., 2010; O'Donovan et al., 2012). Together, this body of evidence suggests that psychosocial stress may impact LTL as one indicator of biological aging; however, other pathways involved in the aging process remain relatively unexplored.

Another important hallmark of biological aging is cellular senescence, a permanent state of cell cycle arrest (López-Otín et al., 2013). A growing literature links stress exposure to the secretion of catecholamines, which can lead to increased production of oxidants and DNA 
damage (Aschbacher et al., 2013; Flint et al., 2007, 2005; Hara et al., 2011; Knickelbein et al., 2008). DNA damage serves an important role in biological aging as excess levels of DNA damage can initiate cellular senescence (Campisi, 2005). DNA damage can also accelerate the shortening of telomeres, which can result in cellular senescence when telomeres reach a critically short length (Blackburn, 2000; Choi et al., 2008; Fumagalli et al., 2012). Importantly, the senescent state has been associated with a heightened release of pro-inflammatory factors, which is thought to be a source of the increased inflammation observed with chronological age, and is suspected to contribute to age-related disease (Campisi and D'Adda Di Fagagna, 2007; Collado et al., 2007; Coppé et al., 2010; Effros et al., 2005; Rodier and Campisi, 2011).

Recent research has identified cell cycle inhibitor $\mathrm{p} 16^{\mathrm{INK} 4 \mathrm{a}}$ as one of the most robust indicators of cellular senescence. Expression of $\mathrm{p} 16^{\mathrm{INK} 4 \mathrm{a}}$ in response to DNA damage and cell stress—-termed "stress-induced" or premature senescence—evolved as a protective mechanism to prevent the replication of damaged cells that could develop into cancer or other malignancies (Campisi and D'Adda Di Fagagna, 2007). However, pervasive cellular senescence via enhanced $\mathrm{p} 16^{\mathrm{INK} 4 \mathrm{a}}$ can itself become damaging and accelerate aging through heightened inflammation and reduced stem cell and tissue function (Campisi, 2005; Coppé et al., 2010). Expression of $\mathrm{p} 16^{\mathrm{INK} 4 \mathrm{a}}$ has been proposed as a biomarker of aging, as it correlates highly with chronological age across several tissues, and is linked to the highest number of age-related pathologies, including cardiovascular disease, arthritis, diabetes, Alzheimer's disease, and premalignant tumors (Liu et al., 2009; López-Otín et al., 2013; Ressler et al., 2006). Recent studies with mice demonstrated that removal of $\mathrm{p} 6^{\mathrm{INK} 4 \mathrm{a}}$ positive cells prevented or slowed the deterioration of several tissues and organs, and delayed tumor growth (Baker et al., 2011), and reduced metastasis in mice exposed to cytotoxic cancer treatments (Demaria et al., 2017). These studies suggest that senescent cells contribute to the promotion and progression of age-related deterioration and disease processes in mice. To date, however, only two studies have investigated $\mathrm{p} 16^{\mathrm{INK} 4 \mathrm{a}}$ in humans, finding enhanced $\mathrm{p} 16^{\mathrm{INK} 4 \mathrm{a}}$ in individuals with depression compared to controls (Teyssier et al., 2012), and increased p $16^{\mathrm{INK} 4 \mathrm{a}}$ following partial sleep deprivation in older adults (Carroll et al., 2016a). Importantly, the association between psychosocial stress and gene expression of $\mathrm{p} 16^{\mathrm{INK} 4 \mathrm{a}}$ has not yet been investigated.

The present study extends the literature on associations between psychosocial stress and markers of biological aging in three important ways. First, whereas the majority of previous research investigated associations between a single measure of stress and biomarker of aging, we adopted an intensive repeated measures design that included an interview-based assessment of chronic stress exposure, and two measures of stress responses: the Perceived Stress Scale (Cohen et al., 1983) and daily reports of stress appraisals over a 56-day period. This design allowed for a more comprehensive and ecologically valid assessment of stress exposure and responses than prior studies relying on single retrospective measures. Second, this study examined two important measures of biological aging: a more established marker, LTL, and a more novel marker, $\mathrm{p} 16^{\mathrm{INK} 4 \mathrm{a}}$. Finally, we investigated psychosocial stress in a sample of parents during mid-life, when stress-related vulnerability to age-associated disease may begin to emerge. Based on previous research on stress and LTL, we hypothesized that parents with greater exposure to chronic stress and reports of global and daily perceived 
stress would have shorter LTL. In light of emerging evidence about the role of $\mathrm{p} 16^{\mathrm{INK} 4 \mathrm{a}}$ in cellular aging, we hypothesized that these stress-related effects would extend to cellular senescence, as evidenced by greater $\mathrm{p} 16^{\mathrm{INK} 4 \mathrm{a}}$ expression.

\section{Material and Methods}

\subsection{Participants}

Participants were 73 adults from 40 heterosexual couples (55\% female) with an average age of 43.0 years $(S D=7.2$; range: $27.6-61.9)$ and at least one child between 8 and 13 years of age. ${ }^{1}$ The majority of participants were White/Non-Hispanic (42.5\%), followed by Latino/ Hispanic (23.3\%), African American (20.5\%), Asian (11.0\%), Native American (1.4\%), and self-identified mixed ethnicity (1.4\%). Participants' median education was 12.4 years, and median personal income was within the \$31,851-\$64,250 tax bracket in 2009-2012 (\$34,001-\$82,400 in the third year of data collection). At study entry, the majority of participants were employed full-time (61.6\%), with a smaller proportion employed part-time $(15.1 \%)$, or as homemakers (12.3\%). Most participants were married (97.3\%) with an average relationship length of 15.5 years $(S D=5.9$; range: $1.3-27.6)$.

Participants were recruited as part of a larger study on the effects of the family environment on immune function and risk for upper respiratory infection (Robles et al., 2016, 2018). Families in the larger study were recruited in the Los Angeles area from 2009 to 2012 through advertising in local elementary and middle schools, libraries and recreation centers, medical clinics, newspapers, and direct mailings using a marketing list of families within five miles of the University of California, Los Angeles, that were selected based on zip-code level income.

\subsection{Procedures}

At study entry, participants completed an interview-based assessment of their objective stress exposures, followed by an online questionnaire to assess their subjective stress responses. During a subsequent 56-day daily diary period, participants completed online surveys each evening before bedtime that included daily stress appraisals and other items related to mood and family interactions. At the end of the diary period, participants provided a blood sample that was used to assess markers of cellular aging: LTL and cellular senescence signal p16 ${ }^{\mathrm{INK} 4 \mathrm{a}}$. If participants reported any of the following symptoms on the day of the blood draw, the blood draw was rescheduled for a later date: cold or flu-like symptoms such as sore throat, runny nose, or cough, a fever, night sweats, nausea, vomiting, or diarrhea, blood in stool or urine, frequent urination, and/or a skin rash or abscess. There were no restrictions on what participants could not consumer prior to the draw. Blood samples were collected between 12 p.m. and 7 p.m. at the UCLA Clinical Laboratory through antecubital venipuncture in PAXgene Blood RNA tubes (Qiagen), chilled, and

\footnotetext{
${ }^{1}$ The present sample was comprised of one participant with a body mass index of 44.5 that was 3.0 standard deviations above the sample mean, which is the cutoff we used to identify outliers. When we excluded this participant from the analyses, results from the random effects models were largely equivalent, except that the coefficient for the adjusted model with accumulated daily stress appraisals predicting $\mathrm{p} 16^{\mathrm{INK} 4 \mathrm{a}}$ mRNA was reduced to marginal statistical significance $(b=.010, p=.06)$. Given that this participant's scores on the main criterion variables were within 3 standard deviations from the mean, we included the participant in the analyses.
} 
transported to the UCLA Health Psychology Laboratory for storage at $-80^{\circ} \mathrm{C}$. Given that the diary protocol involved a significant time commitment for participants, the blood sample was not required for participation in the study; therefore, the present sample includes 73 of the 86 enrolled adult participants who chose to provide a blood sample. Participants who provided blood samples did not differ significantly in their age, gender distribution, education, employment status, income, or BMI from those who did not provide samples. Blood samples were collected between 1 to 85 days after the end of the daily diary period (median $=15$ days), with the exception of one family that provided samples two days before the end of the diary period.

\subsection{Measures}

2.3.1. Chronic stress exposure-Participants were separately administered the 60 - to 90-minute semi-structured UCLA Life Stress Interview (LSI; Hammen, 1991), which was designed to assess exposure to chronic stressors in several domains (e.g., family relationships, friendships, work, finances, health) over the past six months, independent of the participants' subjective appraisals or emotional reactions to the stressors. Trained interviewers asked a series of open-ended questions for each domain, with additional probes as necessary to obtain sufficient information to score the domain from 1 (exceptionally good conditions) to 5 (extreme adversity). The present study utilized an adapted version of the interview, which included questions that specifically asked about conflict and warmth in the marital (e.g., "Do you ever argue or fight with your spouse?") and parent-child (e.g., "How do you feel about your time together with your child?") relationships (Robles et al., 2016). Ratings for the thirteen domains were averaged to create a chronic stress exposure score for each participant.

2.3.2 Perceived Stress Scale-After the initial visit, participants completed the 10item version of the Perceived Stress Scale (Cohen et al., 1983), a well-established and validated measure of the degree to which an individual appraises his/her life as stressful. Items on the scale assessed different aspects of perceived stress, including feeling stressed, upset, or angry, and unable to cope with or control important things in life, which participants rated on a scale from 0 (never) to 4 (very often) over the previous week. Items were summed to create a total score, with higher scores indicating greater perceived stress.

2.3.3. Accumulated daily stress appraisals-During the subsequent 8 -week daily diary period, participants provided reports of daily stress appraisals by rating how accurately the adjectives "stressed" and "overwhelmed" described how they felt that day on a scale from 1 (completely inaccurate) to 4 (completely accurate). Items were designed to be consistent with and complementary to daily positive and negative mood items utilized in this and previous studies (Cohen et al., 2006; Doyle et al., 2006). In order to assess the accumulation of stress appraisals over the 56-day period, we first created a categorical variable in which participant responses of a "3" (mostly accurate) or " 4 " (completely accurate) on either of the two items for a given day represented a stress appraisal for that day. We then calculated the total number (sum) of stressful days for each participant over the 56-day period, divided by the number of diary days each participant completed, and multiplied by 100 to create a percentage score. On average, the percentage of days 
participants endorsed feeling "stressed" was $18.56(S D=19.56)$ and "overwhelmed" was $12.90(S D=16.65)$, and the two items were highly correlated $(r=.80, p<.001)$. In addition, the average participant completed $52.37(S D=7.48)$ out of 56 daily diaries. ${ }^{2}$

2.3.4. Leukocyte telomere length (LTL)_Assessment of LTL in whole blood was performed at the UCLA Cousins Center for Psychoneuroimmunology Aging Biology and Behavior Laboratory using established real-time quantitative polymerase chain reaction (PCR) methodology as described in previously published protocols (Carroll et al., 2016b; Cawthon, 2002; Robles et al., 2016). Briefly, genomic DNA was extracted from leukocytes using PAXgene Blood DNA kits (Qiagen), and diluted to $5 \mathrm{ng} / 10 \mathrm{uL}$. Each sample well included $5 \mathrm{ng}$ of sample, iQ SYBR Green PCR Master Mix (BioRad), and primers (Invitrogen) for Tel1b and Tel2b for the telomere plate (which amplify the repeating DNA sequences of the telomere), or HGB1 and HGB2 for the single copy HGB plate. A notemplate control was included in all reactions and used for background subtraction. Real time PCR was performed using the Biorad iCycler thermal cycler, which is equipped to read fluorescence at each cycle. Standard curves were generated on each plate using serial dilution of TaqMan CTL Genomic DNA (15 ng-0.94 ng; Applied Biosystems). The standard curve was used to confirm PCR efficiency of $90 \%$ to $105 \%$ for all plates, and to control for plate-to-plate variation. Samples were run in triplicate on two 96-well plates to confirm consistency between wells. Duplicate values were used if one of the triplicates was found to be an outlier. If the coefficient of variation (CV; ratio of the standard deviation to the mean) was $>10 \%$ between duplicates, samples were re-run. Inter-assay (i.e., between-plate) and intra-assay (i.e., within-person) CVs were all $<5 \%$; therefore, duplicate and triplicate values were averaged for analysis. Using the standard curve method, cycle threshold (CT) values were plotted on the standard curve to estimate a concentration value for telomere DNA repeat sequences (T) or the HGB single-copy gene (S). Telomere length values are expressed as the T/S ratio of the estimated concentration of the telomere DNA repeats divided by the single-copy gene. The $\mathrm{T} / \mathrm{S}$ ratio served as the criterion variable in analyses involving LTL.

2.3.5. Cellular senescence marker $\mathbf{p} 16^{\mathrm{INK}} \mathbf{\mathrm { a }}$-Following the procedures outlined above, peripheral blood was collected and stored in PAXgene Blood RNA tubes (Qiagen). Specimens were assayed in a single batch, with RNA extracted (Qiagen RNeasy), tested for suitable mass (Nanodrop ND1000) and integrity (Agilent Bioanalyzer), and converted to fluorescence-tagged cRNA (Ambion TotalPrep). RNA samples were assayed by microarraybased genome-wide transcriptional profiling (Illumina Human HT-12 v4 BeadArrays) following the manufacturer's standard protocol in the UCLA Neuroscience Genomics Core Laboratory. All samples yielded valid results according to standard quality assurance methods (e.g., median probe fluorescence intensity > 100 units; (Robles et al., 2018)). For the present analyses, expression of mRNA for the p16 $6^{\mathrm{INK} 4 \mathrm{a}}$-encoding gene $C D K N 2 A$ served as the measure of cell senescence.

\footnotetext{
2 In addition to this categorical accumulated daily stress appraisals variable, we calculated a continuous variable in which we first averaged participants' daily responses to the "stressed" and "overwhelmed" items, which were highly correlated $(r=.90, p<.001)$, and then averaged participants' scores over the 56-day diary period. The pattern of results from the random effects models with the continuous daily stress variable predicting telomere length and $\mathrm{p} 16^{\text {iNK4a }}$ mRNA was equivalent. Results from the random effects model that included all three psychosocial stress variables as predictors of $\mathrm{p} 16^{\mathrm{INK}} 4 \mathrm{a} \mathrm{mRNA}$ were also equivalent.
} 
2.3.6. Covariates-Several variables that might affect estimates of LTL and $\mathrm{p} 16^{\mathrm{INK} 4 \mathrm{a}}$ expression were considered as covariates in the main analyses based on previous research (Cole et al., 2015; Epel and Prather, 2018; Fischer and Riddle, 2017). Variables included participant age, biological sex, Hispanic ethnicity, African American race, educational status, body mass index (BMI, $\left.\mathrm{kg} / \mathrm{m}^{2} ; M=27.9, S D=5.5\right)$, average number of alcoholic drinks per day $(M=2.5, S D=3.5)$, and smoking assessed over the 56-day diary period: none $(65.3 \%)$, fewer than 10 cigarettes per day $(30.1 \%)$, or more than 10 cigarettes per day $(4.2 \%)$. We also considered whether participants had met the criteria for an upper respiratory infection during the diary period (28.8\%), or were taking medication to treat chronic medical conditions such as hypertension $(n=5)$, inflammatory conditions $(n=5)$, hypothyroidism $(n$ $=4)$, depression/anxiety $(n=3)$, and attention-deficit/hyperactivity disorder $(n=1)$.

Covariates also included the percentage of neutrophil, lymphocyte, monocyte, eosinophil, and basophil subsets of total white blood cells, as recent research suggests that variations in leukocyte composition may influence the estimation of and account for some of the agerelated differences in LTL (And and Lansdorp, 2008; Lin et al., 2015; Weng, 2001). Cell subsets were obtained by complete blood count with differential assessed by the UCLA Clinical Laboratory and Pathology Services using standard clinical laboratory methods. Finally, we also considered whether the number of days between the end of the daily diary period and the blood draw might affect estimates of the biological aging markers.

\subsection{Data analysis}

All continuous predictor variables and covariates were normally distributed and were $z$ transformed prior to analysis. Given that the present sample was comprised of 73 adults nested within 40 couples, including two members of a couple in an ordinary least squares regression model would violate statistical assumptions of independence. The intra-class correlation coefficient (which is equivalent to the Pearson correlation coefficient for distinguishable dyads) for LTL was $.25(p=.19)$, and $\mathrm{p} 16^{\mathrm{INK} 4 \mathrm{a}}$ expression was $.05(p=.78)$. Although a small proportion of the variation in the criterion variables was accounted for by the particular dyad or couple in which a participant was nested, we expected that partners' stress scores might be more highly correlated due to a shared environment, which could introduce another potential source of non-independence in the data. We therefore conducted a series of random effects (i.e., multilevel) models using the mixed procedure in SPSS to account for the nesting of participants in dyads (Krull, 2007), with measures of chronic stress exposure, perceived stress, and accumulated daily stress appraisals entered as separate predictor variables and LTL and $\mathrm{p} 16^{\mathrm{INK} 4 \mathrm{a}}$ expression as criterion variables. As recommended by Kenny et al. (2006), models used restricted maximum likelihood (REML) with a compound symmetry covariance structure to estimate fixed effects and random intercepts. Slopes were constrained to be equal across dyads (i.e., the random component for slopes was omitted from the models), as there are not enough lower units to allow the slopes to vary across dyads (Kenny et al., 2006).

A set of preliminary analyses investigated associations between potential covariates (section 2.3.6) and the psychosocial stress and cellular aging variables for inclusion in the main analyses. To test the main hypotheses, we first conducted a set of unadjusted random effects models to examine associations between each of the primary predictor variables and the 
criterion variables, followed by adjusted models that included covariates. To estimate the amount of variance in the criterion variable that was accounted for by each of the primary predictor variables in significant models, we calculated pseudo $\mathrm{R}^{2}$ values using the formula $\mathrm{R}^{2}=1-\left[\left(\mathrm{ss}_{\mathrm{d}}+\mathrm{ss}_{\mathrm{e}}{ }^{2}\right) /\left(\mathrm{ss}_{\mathrm{d}}{ }^{\prime}+\mathrm{ss}_{\mathrm{e}}{ }^{2 \prime}\right)\right]$ where $\mathrm{ss}_{\mathrm{d}}$ is the dyad covariance and $\mathrm{ss}_{\mathrm{e}}{ }^{2}$ is the error covariance derived from the conditional model and the prime indicates covariance derived from the unconditional model (Kenny et al., 2006). A follow-up analysis included the primary predictor variables in a single model to examine the unique contribution of each stress measure in models predicting LTL and $\mathrm{p} 16^{\mathrm{INK} 4 \mathrm{a}}$ expression.

\section{Results}

\subsection{Preliminary Analyses.}

Descriptive statistics for the psychosocial stress and cellular aging variables appear in Table 1. The distribution of chronic stress exposure scores for the sample suggested mild to moderate levels of exposure and was largely consistent with previous research (Miller et al., 2009; Miller and Chen, 2006). In addition, the distribution of perceived stress scores was consistent with previous studies of adults in this age group (Cohen et al., 1983). Chronic stress exposure was moderately correlated with both perceived stress, $I(71)=.44,95 \% C I$ [ $27, .59], p<.001$, and accumulated daily stress, $r(71)=.43[.22 .62], p<.001$, as were perceived stress and accumulated daily stress, $r(71)=.51$, [.32, .67], $p<.001$. LTL was marginally correlated with $\mathrm{p} 16^{\mathrm{INK} 4 \mathrm{a}}$ expression, $r(69)=.24$, [-.03, .47], $p=.05$.

Participant age was inversely correlated with LTL, $I(69)=-.24,[-.46,-.02], p=.05$, such that older participants had shorter LTL; however, age was not related to $\mathrm{p} 16^{\mathrm{INK} 4 \mathrm{a}}$ expression, $r(69)=.14,[-.11, .39], p=.24$. There were no gender differences in LTL, $t(67)=0.32,95 \%$ $C I$ for mean difference $[-0.15,0.14], p=.57$, or $\mathrm{p} 16^{\mathrm{INK} 4 \mathrm{a}}$ expression, $t(67)=-0.91,[-0.03$, $0.01], p=.37$. LTL did not vary by Hispanic ethnicity, $t(67)=0.98,95 \% C I$ for mean difference [-0.13, 0.22], $p=.52$, or African American race, $t(67)=-1.39,[-0.29,0.05], p$ $=.17$. p16 $6^{\mathrm{INK} 4 \mathrm{a}}$ expression also did not vary by Hispanic ethnicity, $t(67)=-0.96,95 \% C I$ for mean difference $[-0.04,0.01], p=.34$, or African American race, $t(67)=-0.40,[-0.03$, 0.02 ], $p=.69$. Finally, participants' educational status, BMI, alcohol use, smoking, diagnosis of upper respiratory infection, and medication use were not related to LTL or p16 $6^{\mathrm{INK} 4 \mathrm{a}}$ expression (all $p s>$.23). Based on previous research and theoretical considerations (Cole et al., 2015; Epel and Prather, 2018; Fischer and Riddle, 2017), we elected to include participant age, biological sex, Hispanic ethnicity, African American race, and BMI as covariates in the main analyses. With respect to cell subsets, the percentage of neutrophil, lymphocyte, monocyte, eosinophil, and basophil subsets of total white blood cells were not significantly correlated with LTL or $\mathrm{p} 16^{\mathrm{INK} 4 \mathrm{a}}$ expression (Appendix A). However, the proportion of eosinophils was marginally correlated with chronic stress exposure, $I(67)=$. $24,[-.04, .47], p=.05$, and perceived stress, $r(67)=.22$, [-.002, .41], $p=.08$, and was considered as a covariate in the main analyses. In addition, the number of days between the daily diary period and the blood draw was marginally correlated with LTL, $r(67)=-.21, p$ $=.08$, but not with expression, $r(71)=.10, p=.37$, and was therefore considered as a covariate in the main analyses. 


\subsection{Psychosocial stress and LTL}

To test the main hypotheses, unadjusted random effects models examined associations between each of the primary predictor variables - chronic stress exposure, perceived stress, and accumulated daily stress appraisals — and LTL, followed by adjusted models that accounted for participant age, sex, BMI, Hispanic ethnicity, and African American race (Table 2). Contrary to hypotheses, chronic stress exposure, perceived stress, and accumulated daily stress appraisals were not significantly associated with LTL. The addition of eosinophil percentages and number of days between the daily diary period and blood draw as covariates in the models did not change the pattern of findings and was therefore omitted from Table 2 .

\subsection{Psychosocial stress and cellular senescence signal $\mathrm{p} 16^{\mathrm{INK} 4 a}$}

A second set of unadjusted and adjusted random effects models examined associations between each of the primary predictor variables - chronic stress exposure, perceived stress, and accumulated daily stress appraisals—and p $16^{\mathrm{INK} 4 \mathrm{a}}$ expression (Table 3). Consistent with hypotheses, individuals with greater chronic stress exposure during the 6 months prior to study entry had marked elevations in $\mathrm{p} 16^{\mathrm{INK} 4 \mathrm{a}}$ expression, $b=0.011,95 \% C I[0.001$, 0.022], $p=.04$ (Figure 1, left). We calculated the pseudo $\mathrm{R}^{2}$ following the formula presented in the data analysis section (2.4). The pseudo $\mathrm{R}^{2}$ for the unadjusted model suggested that chronic stress exposure accounted for approximately $8 \%$ of the variance in $\mathrm{p} 16^{\mathrm{INK} 4 \mathrm{a}}$ expression. Follow-up analyses that explored associations between specific domains of chronic stress exposure and $\mathrm{p} 16^{\mathrm{INK} 4 \mathrm{a}}$ expression suggested that marital conflict, $b=0.011$, 95\% $C I[0.001,0.022], p=.04$, and work-related stress, $b=0.011,95 \% C I[0.0004,0.021]$, $p=.04$, may have been driving the observed association between chronic stress and p16 $6^{\mathrm{INK} 4 \mathrm{a}} \mathrm{mRNA}$. In addition, individuals who reported greater perceived stress in the week prior to study entry had elevated $\mathrm{p} 16^{\mathrm{INK} 4 \mathrm{a}} \mathrm{mRNA}, b=0.020,95 \% C I[0.010,0.030] p<$. 001 (Figure 1, middle). The pseudo $\mathrm{R}^{2}$ for the unadjusted model suggested that perceived stress accounted for approximately $14 \%$ of the variance in $\mathrm{p} 16^{\mathrm{INK} 4 \mathrm{a}}$ expression levels. Similarly, individuals with greater accumulated daily stress over the 56-day diary period had increased p16 $6^{\mathrm{INK} 4 \mathrm{a}}$ expression, $b=0.013,95 \% C I[0.002,0.023], p=.02$ (Figure 1, right). ${ }^{3}$ The pseudo $\mathrm{R}^{2}$ for the unadjusted model suggested that accumulated daily stress accounted for approximately $8 \%$ of the variance in $\mathrm{p} 16^{\mathrm{INK} 4 \mathrm{a}}$ expression. The addition of eosinophil percentages and number of days between the daily diary and blood draw as covariates in the models did not change the pattern of findings and was therefore omitted from Table 3.

\footnotetext{
${ }^{3}$ To address the possibility that daily stress appraisals were capturing variations in daily negative mood more broadly, ancillary analyses examined accumulated daily negative mood as a predictor of $\mathrm{p} 16^{\mathrm{INK} 4 \mathrm{a}} \mathrm{mRNA}$. During the diary period, participants rated eight adjectives in total that represented four subcategories of negative mood: stress (stressed, overwhelmed), anxiety (tense, on edge), anger (angry, hostile) and sadness (sad, unhappy). The other adjectives were recoded following the same procedure as the accumulated daily stress variable, in which participant responses of a " 3 " or " 4 " on any of the eight items for a given day represented a negative mood rating for that day. We then calculated the total number (sum) of negative mood days for each participant over the 56-day period, divided by the number of diary days each participant completed, and multiplied by 100 to create a percentage score. We also created a percentage score for each of the negative mood subscales. The subscales were significantly intercorrelated (Appendix B, Table 5). The accumulated daily negative mood composite was significantly associated with $\mathrm{p} 16^{\mathrm{INK}} 4 \mathrm{a}$ expression in the unadjusted model; however, the association was reduced to marginal significance in the adjusted model. Follow-up analyses that included the four daily negative mood subscales in a single model revealed that only the daily anger subscale was marginally associated with p16 $6^{\mathrm{INK}} 4 \mathrm{a}$ expression (Appendix B, Table 6) in the unadjusted model; however, the association was reduced to non-significance in the adjusted model.
} 
A follow-up analysis included the primary predictor variables in a single model to examine the unique contribution of each stress measure in models predicting $\mathrm{p} 16^{\mathrm{INK} 4 \mathrm{a}}$ expression (Appendix C). In the combined adjusted model, the coefficient for perceived stress ( $b=$ $0.017,95 \% C I[0.004,0.029], p=.01)$ remained statistically significant, whereas the coefficients for chronic stress exposure $(b=0.005,95 \% C I[-0.006,0.016], p=.38)$ and accumulated daily stress $(b=0.002,95 \% C I[-0.010,0.014], p=.76)$ were reduced to statistical non-significance. The pseudo $\mathrm{R}^{2}$ for the unadjusted model suggested that the psychosocial stress variables together accounted for approximately $15 \%$ of the variance in p16 ${ }^{\mathrm{INK} 4 \mathrm{a}} \mathrm{mRNA}$ abundance.

\section{Discussion}

The present study investigated associations between mid-life parents' exposures and responses to psychosocial stress and two markers of cellular aging-LTL and cellular senescence signal $\mathrm{p} 16^{\mathrm{INK} 4 \mathrm{a}}$ — within an intensive repeated measures design that combined interview-based, questionnaire, and daily diary reports of stress. As expected, parents with higher chronic stress exposure in the six months prior to study entry showed elevated p $16^{\mathrm{INK} 4 \mathrm{a}}$ expression, a robust indicator of cellular senescence. In addition, parents who perceived their lives as more stressful in the week prior to study entry and reported a greater percentage of stressful days over the 8-week diary period also showed elevations in p16 $6^{\mathrm{INK} 4 \mathrm{a}}$ expression (although the coefficient for accumulated daily stress dropped below the threshold for statistical significance when adjusting for covariates). A follow-up analysis suggested that of the three stress measures, participants' more global perceptions of stressincluding feeling stressed, upset, and unable to control important things in life —was most robustly associated with $\mathrm{p} 16^{\mathrm{INK} 4 \mathrm{a}} \mathrm{mRNA}$ levels. Although we did not make a priori hypotheses about the specificity of the stress measures as predictors of cellular aging, this finding is consistent with the larger literature on stress and health (Epel et al., 2018), which suggests that individuals' cognitive and emotional experience of a stressor may have a more profound impact on physiology than exposure to the stressful situation alone. Together, the findings related to $\mathrm{p} 16^{\mathrm{INK} 4 \mathrm{a}}$ expression suggest that parents who are exposed to higher levels of chronic stress or perceive their life experiences as more stressful may show signs of accelerated biological aging in mid-life that have not yet manifested as a disease process but may place them on trajectories of increased risk, as cellular senescence is a common pathophysiology of age-related disease. Indeed, recent research suggests that cellular senescence, through heightened release of pro-inflammatory factors and reduced stem cell and tissue function, contributes to age-related deterioration and other malignancies such as cardiovascular disease, arthritis, diabetes, and pre-malignant tumors (Campisi and D'Adda Di Fagagna, 2007).

Contrary to expectations, chronic stress exposure, perceived stress, and accumulated daily stress appraisals did not significantly relate to LTL in this sample of parents. These findings are contrary to the majority of studies that demonstrated a link between stress and LTL, but consistent with some studies that did not observe an association. The lack of findings with LTL raises several important considerations with respect to the measurement and potential significance of LTL in a sample of parents during mid-life. First, recent research suggests that the process of telomere maintenance is more dynamic than researchers originally 
understood. For instance, research on basic telomere biology suggests that, particularly under stress, LTL at a given measurement time can depend on cell distribution, replication rate, exposure to damaging agents (e.g., oxidative stress, inflammation), and telomerase activity, an enzyme that functions to elongate telomeres (Aviv, 2008). The present analysis was able to adjust for cell distribution but unable to account for telomerase activity. Future research will benefit from the measurement of both LTL and telomerase, as short LTL with high telomerase activity has been associated with heightened allostatic load and impoverished psychosocial resources (Epel et al., 2004).

A second explanation for the lack of findings may relate to the demographics of the present sample with respect to the severity or duration of the reported stressors and the age of the study cohort. Whereas several previous investigations of associations between stress and LTL recruited participants based on their exposure to a chronic stressor such as caregiving (Damjanovic et al., 2007; Epel et al., 2004), the present study aimed to extend these findings to a more normative population with common parenting stressors that typically occur during middle adulthood. There is some evidence to suggest that individuals may be more susceptible to telomere attrition during higher-risk developmental periods such as early childhood and older adulthood when the immune system may not be as robust (Carroll et al., 2013; Kiecolt-Glaser et al., 2011; Moffitt et al., 2013; Puterman et al., 2010; Robles et al., 2016; Shalev et al., 2013). In a mid-life sample, it is possible that the mild to moderate severity of the stressors reported in this study were not severe enough to have a significant impact on telomere biology. Although stress scores in this sample were largely consistent with previous research (Cohen et al., 1983; Miller and Chen, 2006), the studies were typically comprised of higher-risk populations and larger samples than the present study. It is also possible that cumulative wear and tear from chronic or repeated stressful experiences can lead to premature replicative senescence in middle age; however, in a relatively healthy sample, the effects of such cumulative stress exposure on LTL may unfold over a longer period of time than the 8 month period that was assessed in present study. Finally, recent research suggests that the relation between psychosocial stress and LTL may be more nuanced than the main effect models we tested. For example, previous studies have found that participant sex and protective health behaviors such as diet and exercise may moderate the effects of stress on LTL (Puterman et al., 2015, 2010; Puterman and Epel, 2012). The present study was not powered test moderators due to the relatively small sample of adults. However, in the absence of main effects, we performed an ad-hoc analysis to explore participant sex as a moderator in associations between stress and LTL but no significant effects were observed. The investigation of participant characteristics and health behaviors remains an important area for future research.

Findings from this study should be considered in light of several limitations, which suggest directions for future research. Most notably, the sample size was relatively small, which reduced the statistical power to detect potential moderating effects of participant sex, ethnicity/race, and protective health behaviors in associations between stress and biological aging. Future research would benefit from larger samples to more fully address these questions. Second, although the study included measures of stress that spanned several months, the single-occasion measurement of cellular aging markers precluded the investigation of change in LTL and the accumulation of senescent cells over the course of 
the study. Prospective longitudinal designs that include repeated assessments of psychosocial stress and markers of biological aging will be important in future work to address questions about the relative contribution of psychosocial stress to changes in cellular aging dynamics over time. Third, it was somewhat surprising that the study did not reveal a significant association between participants' chronological age and $\mathrm{p} 16^{\mathrm{INK} 4 \mathrm{a}}$ expression, given that two prior studies did report a correlation (Liu et al., 2009; Teyssier et al., 2012). This may be due in part to the present sample of participants, which was comprised of healthy, middle-aged parents with a more restricted age range than previous studies of healthy adults (i.e., Liu et al [2009] included adults aged 18-80 years), and it is possible that an association may have been observed had the sample included a greater number of older adults (i.e., greater than 65 years). Regardless, the lack of association is consistent with the hypothesis that psychosocial stress may lead to accelerated or premature cellular senescence (i.e., that is not ageassociated) in mid-life; however, future research to address this question is warranted.

Finally, LTL and gene expression of cellular senescence signal p16 $6^{\mathrm{INK} 4 \mathrm{a}}$ are only two (empirically distinct) markers of a dynamic and multi-faceted biological aging process that also includes mechanisms related to inflammation, DNA damage, cell stress, mitochondrial dysfunction, and altered DNA methylation (López-Otín et al., 2013). This study was unable to assess these mechanisms; however, several studies with animal models of stress and in vitro work have demonstrated that the activation of the sympathoadrenal system, or exposure to catecholamine, can directly alter DNA damage and oxidative stress pathways. In particular, mice that underwent a 2-hour restraint stress task showed greater DNA damagerelated gene expression compared to controls (Flint et al., 2005) and mice infused with a synthetic analogue of adrenaline for four weeks showed greater DNA damage compared to mice infused with saline (Hara et al., 2011). In addition, murine cells exposed to physiological concentrations of catecholamines (i.e., epinephrine, norepinephrine) or cortisol showed five-fold increases in DNA damage compared to untreated cells (Flint et al., 2007). In a human study, young adults that participated in an acute stressor task had greater oxidative damage than those in the control group (Knickelbein et al., 2008). Another study found that postmenopausal women's cortisol reactivity in response to an acute stressor task mediated the association between perceived stress and oxidative damage for those undergoing chronic caregiving stress but not age-matched controls (Aschbacher et al., 2013). These findings provide preliminary evidence that stress impacts DNA damage pathways through frequent or sustained activation of the sympathoadrenal system, and other research has linked DNA damage to the initiation of cellular senescence and shortening of telomeres (Campisi, 2005; Fumagalli et al., 2012). However, additional empirical investigations are warranted to more fully elucidate this and other potential pathways through which stress may affect accelerated biological aging and age-associated disease risk, and to examine whether alterations in these pathways can inhibit the impact of stress on biological aging.

Despite these limitations, the present study extends the existing literature on the impact of psychosocial stress on biological aging pathways in several important ways. First, it is the first to link measures of psychosocial stress to gene expression of $\mathrm{p} 16^{\mathrm{INK} 4 \mathrm{a}}$, a key molecular indicator of cellular senescence. Although the present study did not directly measure DNA damage or cell (i.e., oxidative) stress responses, these findings provide preliminary evidence of a "stress-induced" senescence pathway that is independent of telomere exhaustion 
(Campisi and D'Adda Di Fagagna, 2007). This telomere-independent pathway may be particularly meaningful in light of evidence suggesting that telomeres can lengthen over time through activation of the enzyme telomerase (Epel et al., 2009; Farzaneh-Far et al., 2010; Puterman and Epel, 2012; Shalev, 2012), whereas p16 ${ }^{\mathrm{INK} 4 \mathrm{a}}$-induced cellular senescence is typically an irreversible process (Campisi and D'Adda Di Fagagna, 2007; López-Otín et al., 2013). Recent research with animal models suggests that the number of senescent cells in the body can be reduced using a pharmaceutical agent that selectively initiates cell death (Baker et al., 2011). Second, this study was the first to demonstrate associations between daily stressful experiences and biological aging processes. Moreover, the accumulated daily stress measure in this study had a high degree of precision as it was derived from 56 days of diary reports, making it particularly ecologically valid. Finally, on a methodological level, despite the lack of findings with respect to LTL, this study was well positioned to reliably assess telomere length while accounting for the cell subsets that were present in the leukocyte pools that, if unmeasured, have the potential to confound results. For instance, lymphocytes show greater telomere attrition than other leukocyte subsets (Lin et al., 2015) and it is critical that future research in this area account for these differences, either by measuring cell subset percentages or investigating single cell TL.

\section{Conclusions}

There is now a sizeable literature which suggests that exposure to various forms of chronic stressors and subjective experiences of stress can impact key biological aging pathways, including increasing DNA damage and shortening LTL (Aschbacher et al., 2013; Puterman et al., 2015), which may increase risk for a variety of age-related diseases. This study begins to fill a gap in the literature by extending these stress-related effects to cellular senescence, a state of stable cell growth arrest. Mid-life parents who reported greater chronic stress exposure, perceived stress, and accumulated daily stress appraisals showed increased gene expression of cellular senescent signal $\mathrm{p} 16^{\mathrm{INK} 4 \mathrm{a}}$. Through its comprehensive assessment of stress, this study also extends previous work by complementing more traditional measures of stress exposure and perceived stress with intensive repeated assessments of daily experiences that increase the accuracy and ecological validity of participant reports, and linking these measures to an accumulation of senescent cells. As such, findings support the hypothesis that chronic stress is associated with accelerated aging by inducing cellular senescence, a common pathophysiology in age-related diseases.

\section{Acknowledgements:}

We would like to thank Richard Slatcher and Gayla Margolin for their invaluable contributions to this project. Funding:

This work was supported by the National Institutes of Health [R03HD0077387], William T. Grant Foundation [9333], and UCLA Cousins Center for Psychoneuroimmunology. Funding sources had no involvement in the study design, data collection, analysis and interpretation, drafting of the manuscript, or the decision to submit the manuscript for publication. 


\section{APPENDIX A}

\section{Table 4}

Correlations between psychosocial stress and cellular aging variables and cell subsets $(N=$ 71)

\begin{tabular}{|c|c|c|c|c|c|}
\hline & \multicolumn{5}{|c|}{ Cell subsets } \\
\hline & Neutrophil & Lymphocyte & Monocyte & Eosinophil & Basophil \\
\hline \multicolumn{6}{|l|}{ Psychosocial stress variables } \\
\hline Chronic stress exposure & $-.12[-.38, .18]$ & $.05[-.22, .30]$ & $.21[-.02, .42]$ & $.23[-.07, .47]$ & $-.08[-.36, .22]$ \\
\hline Perceived stress & $-.12[-.37, .15]$ & $.10[-.16, .34$ & $.01[-.28, .27]$ & $.22[.01, .42]$ & $-.04[-.26,19]$ \\
\hline Accumulated daily stress & $-.13[-.37, .14]$ & $.08[-.18, .31]$ & $.07[-.18, .32]$ & $.19[.04, .40]$ & $-.03[-.29, .24]$ \\
\hline \multicolumn{6}{|l|}{ Cellular aging variables } \\
\hline Leukocyte telomere length & $-.11[-.36, .14]$ & $.11[-.15, .36]$ & $.09[-.14, .31]$ & $-.06[-.27, .17]$ & $-.06[-.28, .18]$ \\
\hline $\begin{array}{l}\text { Cellular senescence signal } \\
\text { p16 }\end{array}$ & $-.01[-.24, .23]$ & $-.04[-.27, .20]$ & $.04[-.20, .25]$ & $.16[-.07, .36]$ & $-.02[-.24, .21]$ \\
\hline
\end{tabular}

Note. Cell subsets refer to percentages of total white blood cells. Brackets indicate $95 \%$ confidence intervals based on 10,000 bootstrapped samples. Bold type indicates marginally significant correlation coefficients, $p<.10$.

\section{APPENDIX B}

\section{Table 5}

Intercorrelations between accumulated daily negative mood subscales

\begin{tabular}{lcccc}
\hline Variables & $\mathbf{1 .}$ & $\mathbf{2 .}$ & $\mathbf{3 .}$ & $\mathbf{4 .}$ \\
\hline 1. Daily stressed mood subscale & - & $.80^{* *}$ & $70^{* *}$ & $.36^{* *}$ \\
2. Daily anxious mood subscale & - & $.57^{* *}$ & $.24^{*}$ \\
3. Daily angry mood subscale & & & - & $.27^{*}$ \\
4. Daily sad mood subscale & & & & - \\
\hline Note. & & & & \\
$* *$ \\
$p<.01$, \\
$p^{*}<.05$.
\end{tabular}

Table 6

Random effects models with accumulated daily negative mood predicting cellular senescence marker $\mathrm{p} 16^{\mathrm{INK} 4 \mathrm{a}}$

\begin{tabular}{lcccccc}
\hline & \multicolumn{3}{c}{ Unadjusted models $(\mathbf{N}=\mathbf{7 3})$} & \multicolumn{4}{c}{ Adjusted models $(\boldsymbol{N}=\mathbf{7 2})$} \\
Models & $\boldsymbol{b}$ & $\boldsymbol{p}$ & $\mathbf{9 5 \%} \mathbf{C I}$ & $\boldsymbol{b}$ & $\boldsymbol{p}$ & $\mathbf{9 5 \%} \mathbf{C I}$ \\
\hline 1. Daily negative mood composite & 0.012 & .03 & $0.001,0.022$ & 0.011 & .06 & $-0.0003,0.022$ \\
2. Daily stressed mood subscale & 0.001 & .89 & $-0.017,0.020$ & 0.004 & .72 & $-0.016,0.023$ \\
$\quad$ Daily anxious mood subscale & 0.005 & .54 & $-0.011,0.022$ & 0.004 & .64 & $-0.013,0.021$ \\
Daily angry mood subscale & 0.012 & .09 & $-0.002,0.025$ & 0.010 & .19 & $-0.005,0.024$ \\
$\quad$ Daily sad mood subscale & -0.001 & .89 & $-0.011,0.010$ & -0.002 & .68 & $-0.014,0.009$ \\
\hline
\end{tabular}

Note. $\mathrm{CI}=$ confidence interval. All continuous predictor variables are $z$-transformed. Adjusted models account for participant age, biological sex, body mass index, and Hispanic ethnicity, and African American race. 


\section{APPENDIX C}

\section{Table 7}

Random effects model with psychosocial stress variables predicting cellular senescence marker $\mathrm{p} 16^{\mathrm{INK} 4 \mathrm{a}}$

\begin{tabular}{lcccccc}
\hline & \multicolumn{3}{c}{ Unadjusted model $(\boldsymbol{N}=\mathbf{7 1})$} & \multicolumn{3}{c}{ Adjusted model $(\boldsymbol{N}=\mathbf{7 0})$} \\
& $\boldsymbol{\beta}$ & $\boldsymbol{p}$ & $\mathbf{9 5 \%} \mathbf{C I}$ & $\boldsymbol{\beta}$ & $\boldsymbol{p}$ & $\mathbf{9 5 \%} \mathbf{C I}$ \\
\hline Chronic stress exposure & 0.006 & .24 & $-0.004,0.017$ & 0.005 & .38 & $-0.006,0.016$ \\
Perceived stress & 0.012 & .05 & $0.0003,0.024$ & 0.017 & .01 & $0.004,0.029$ \\
Accumulated daily stress & 0.005 & .43 & $-0.007,0.016$ & 0.002 & .76 & $-0.010,0.014$ \\
Age & & & & 0.007 & .15 & $-0.003,0.017$ \\
Sex & & & & -0.002 & .84 & $-0.023,0.019$ \\
Body mass index & & & & 0.002 & .65 & $-0.008,0.013$ \\
Hispanic/Latino (yes/no) & & & & 0.025 & .06 & $-0.001,0.051$ \\
African American (yes/no) & & & & -0.001 & .95 & $-0.027,0.025$ \\
\hline
\end{tabular}

Note. $\mathrm{CI}=$ confidence interval. All continuous predictor variables are $z$-transformed.

\section{References}

Ahola K, Sirén I, Kivimäki M, Ripatti S, Aromaa A, Lönnqvist J, Hovatta I, 2012 Work-related exhaustion and telomere length: A population-based study. PLoS One 7 10.1371/journal.pone. 0040186

And GA, Lansdorp PM, 2008 Telomeres and Aging in Mammals. Physiol. Rev 557-579. 10.1152/ physrev.00026.2007. [PubMed: 18391173]

Aschbacher K, O’Donovan A, Wolkowitz OM, Dhabhar FS, Su Y, Epel E, 2013 Good stress, bad stress and oxidative stress: Insights from anticipatory cortisol reactivity. Psychoneuroendocrinology 38 , 1698-1708. 10.1016/j.psyneuen.2013.02.004 [PubMed: 23490070]

Aviv A, 2008 The epidemiology of human telomeres: Faults and promises. Journals Gerontol. - Ser. A Biol. Sci. Med. Sci 63, 979-983. 10.1093/gerona/63.9.979

Baker DJ, Wijshake T, Tchkonia T, Lebrasseur NK, Childs BG, Van De Sluis B, Kirkland JL, Van Deursen JM, 2011 Clearance of p16 Ink4a-positive senescent cells delays ageing-associated disorders. Nature 479, 232-236. 10.1038/nature10600 [PubMed: 22048312]

Blackburn EH, 2000 Telomere states and cell fates. Nature 408, 53-56. 10.1038/35040500 [PubMed: 11081503]

Campisi J, 2005 Senescent cells, tumor suppression, and organismal aging: Good citizens, bad neighbors. Cell 120, 513-522. 10.1016/j.cell.2005.02.003 [PubMed: 15734683]

Campisi J, D’Adda Di Fagagna F, 2007 Cellular senescence: When bad things happen to good cells. Nat. Rev. Mol. Cell Biol 10.1038/nrm2233

Carroll JE, Cole SW, Seeman TE, Breen EC, Witarama T, Arevalo JMG, Ma J, Irwin MR, 2016a Partial sleep deprivation activates the DNA damage response (DDR) and the senescence-associated secretory phenotype (SASP) in aged adult humans. Brain. Behav. Immun 51, 223-229. 10.1016/ j.bbi.2015.08.024 [PubMed: 26336034]

Carroll JE, Diez Roux AV, Fitzpatrick AL, Seeman T, 2013 Low social support is associated with shorter leukocyte telomere length in late life: Multi-ethnic study of atherosclerosis. Psychosom. Med 75, 171-177. 10.1097/PSY.0b013e31828233bf [PubMed: 23370895]

Carroll JE, Esquivel S, Goldberg A, Seeman TE, Effros RB, Dock J, Olmstead R, Breen EC, Irwin MR, 2016b Insomnia and Telomere Length in Older Adults. Sleep 39, 559-564. 10.5665/sleep. 5526 [PubMed: 26715231]

Cawthon RM, 2002 Telomere measurement by quantitative PCR. Nucleic Acids Res 30, 47e-47. 10.1093/nar/30.10.e47 [PubMed: 11752250] 
Cherkas LF, Aviv A, Valdes AM, Hunkin JL, Gardner JP, Surdulescu GL, Kimura M, Spector TD, 2006 The effects of social status on biological aging as measured by white-blood-cell telomere length. Aging Cell 5, 361-365. 10.1111/j.1474-9726.2006.00222.x [PubMed: 16856882]

Choi J, Fauce SR, Effros RB, 2008 Reduced telomerase activity in human T lymphocytes exposed to cortisol. Brain. Behav. Immun 22, 600-605. 10.1016/j.bbi.2007.12.004 [PubMed: 18222063]

Cohen S, Alper CM, Doyle WJ, Treanor JJ, Turner RB, 2006 Positive emotional style predicts resistance to illness after experimental exposure to rhinovirus or influenza A virus. Psychosom. Med 68, 809-815. 10.1097/01.psy.0000245867.92364.3c [PubMed: 17101814]

Cohen S, Kamarck T, Mermelstein R, 1983 A Global Measure of Perceived Stress. J. Health Soc. Behav 24, 385 10.2307/2136404 [PubMed: 6668417]

Cole SW, Levine ME, Arevalo JMG, Ma J, Weir DR, Crimmins EM, 2015 Loneliness, eudaimonia, and the human conserved transcriptional response to adversity HHS Public Access. Psychoneuroendocrinology 62, 11-17. 10.1016/j.psyneuen.2015.07.001 [PubMed: 26246388]

Collado M, Blasco MA, Serrano M, 2007 Cellular Senescence in Cancer and Aging. Cell 130, 223233. 10.1016/j.cell.2007.07.003 [PubMed: 17662938]

Coppé J-P, Desprez P-Y, Krtolica A, Campisi J, 2010 The Senescence-Associated Secretory Phenotype: The Dark Side of Tumor Suppression. Annu. Rev. Pathol. Mech. Dis 5, 99-118. 10.1146/annurev-pathol-121808-102144

Damjanovic AK, Yang Y, Glaser R, Kiecolt-Glaser JK, Nguyen H, Laskowski B, Zou Y, Beversdorf DQ, Weng N.-p., 2007 Accelerated Telomere Erosion Is Associated with a Declining Immune Function of Caregivers of Alzheimer's Disease Patients. J. Immunol 179, 4249-4254. 10.4049/ jimmunol.179.6.4249 [PubMed: 17785865]

Demaria M, O'Leary MN, Chang J, Shao L, Liu S, Alimirah F, Koenig K, Le C, Mitin N, Deal AM, Alston S, Academia EC, Kilmarx S, Valdovinos A, Wang B, De Bruin A, Kennedy BK, Melov S, Zhou D, Sharpless NE, Muss H, Campisi J, 2017 Cellular senescence promotes adverse effects of chemotherapy and cancer relapse. Cancer Discov 7, 165-176. 10.1158/2159-8290.CD-16-0241 [PubMed: 27979832]

Doyle WJ, Gentile DA, Cohen S, 2006 Emotional style, nasal cytokines, and illness expression after experimental rhinovirus exposure. Brain. Behav. Immun 20, 175-181. 10.1016/j.bbi.2005.05.005 [PubMed: 16023829]

Effros RB, Dagarag M, Spaulding C, Man J, 2005 The role of CD8+ T-cell replicative senescence in human aging. Immunol. Rev 205, 147-157. 10.1111/j.0105-2896.2005.00259.x [PubMed: $15882351]$

Epel ES, 2009 Psychological and metabolic stress: A recipe for accelerated cellular aging? Hormones 8, 7-22. 10.14310/horm.2002.1217 [PubMed: 19269917]

Epel ES, Blackburn EH, Lin J, Dhabhar FS, Adler NE, Morrow JD, Cawthon RM, 2004 Accelerated telomere shortening in response to life stress. Proc. Natl. Acad. Sci 101, 17312-17315. 10.1073/ pnas.0407162101 [PubMed: 15574496]

Epel ES, Crosswell AD, Mayer SE, Prather AA, Slavich GM, Puterman E, Mendes WB, 2018 More than a feeling: A unified view of stress measurement for population science. Front. Neuroendocrinol 49, 146-169. 10.1016/j.yfrne.2018.03.001 [PubMed: 29551356]

Epel ES, Merkin SS, Cawthon R, Blackburn EH, Adler NE, Pletcher MJ, Seeman TE, 2009 The rate of leukocyte telomere shortening predicts mortality from cardiovascular disease in elderly men. Aging (Albany.NY) 1, 81-88. 10.18632/aging.100007

Epel ES, Prather AA, 2018 Full-Text. Annu. Rev. Clin. Psychol 14, 371-397. [PubMed: 29494257]

Farzaneh-Far R, Lin J, Epel E, Lapham K, Blackburn E, Whooley MA, 2010 Telomere length trajectory and its determinants in persons with coronary artery disease: Longitudinal findings from the heart and soul study. PLoS One 5, e8612 10.1371/journal.pone.0008612 [PubMed: 20072607]

Fischer KE, Riddle NC, 2018 Sex differences in aging: Genomic instability. Journals Gerontol. - Ser. A Biol. Sci. Med. Sci 73, 166-174. 10.1093/gerona/glx105

Flint MS, Baum A, Chambers WH, Jenkins FJ, 2007 Induction of DNA damage, alteration of DNA repair and transcriptional activation by stress hormones. Psychoneuroendocrinology 32, 470-479. 10.1016/j.psyneuen.2007.02.013 [PubMed: 17459596] 
Flint MS, Carroll JE, Jenkins FJ, Chambers WH, Han ML, Baum A, 2005 Genomic profiling of restraint stress-induced alterations in mouse T lymphocytes. J. Neuroimmunol 167, 34-44. 10.1016/j.jneuroim.2005.06.012 [PubMed: 16026860]

Forlenza M, Latimer JJ, Baum A, 2000 The effects of stress on DNA repair capacity. Psychol. Heal 15, 881-891.

Franceschi C, Campisi J, 2014 Chronic inflammation (Inflammaging) and its potential contribution to age-associated diseases. Journals Gerontol. - Ser. A Biol. Sci. Med. Sci 69, S4-S9. 10.1093/ gerona/glu057

Fumagalli M, Rossiello F, Clerici M, Barozzi S, Cittaro D, Kaplunov JM, Bucci G, Dobreva M, Matti V, Beausejour CM, Herbig U, Longhese MP, Di Fagagna FDA, 2012 Telomeric DNA damage is irreparable and causes persistent DNA-damage-response activation. Nat. Cell Biol 14, 355-365. 10.1038/ncb2466 [PubMed: 22426077]

Glass D, Parts L, Knowles D, Aviv A, Spector TD, 2010 No correlation between childhood maltreatment and telomere length. Biol. Psychiatry 68 10.1016/j.biopsych.2010.02.026

Hara MR, Kovacs JJ, Whalen EJ, Rajagopal S, Strachan RT, Grant W, Towers AJ, Williams B, Lam CM, Xiao K, Shenoy SK, Gregory SG, Ahn S, Duckett DR, Lefkowitz RJ, 2011 A stress response pathway regulates DNA damage through $\beta 2$-adrenoreceptors and $\beta$-arrestin-1. Nature 477, 349 353. 10.1038/nature10368 [PubMed: 21857681]

Harkness KL, Monroe SM, 2016 The assessment and measurement of adult life stress: Basic premises, operational principles, and design requirements. J. Abnorm. Psychol 125, 727-745. 10.1037/ abn0000178 [PubMed: 27254487]

Irwin MR, Cole SW, 2011 Reciprocal regulation of the neural and innate immune systems. Nat. Rev. Immunol 11, 625-632. 10.1038/nri3042 [PubMed: 21818124]

Kananen L, Surakka I, Pirkola S, Suvisaari J, Lönnqvist J, Peltonen L, Ripatti S, Hovatta I, 2010 Childhood adversities are associated with shorter telomere length at adult age both in individuals with an anxiety disorder and controls. PLoS One 5 10.1371/journal.pone.0010826

Kiecolt-Glaser JK, Gouin JP, Weng NP, Malarkey WB, Beversdorf DQ, Glaser R, 2011 Childhood adversity heightens the impact of later-life caregiving stress on telomere length and inflammation. Psychosom. Med 73, 16-22. 10.1097/PSY.0b013e31820573b6 [PubMed: 21148804]

Knickelbein KZ, Flint M, Jenkins F, Baum A, 2008 Psychological stress and oxidative damage in lymphocytes of aerobically fit and unfit individuals. J. Appl. Biobehav. Res 13, 1-19. 10.1111/j. 1751-9861.2008.00025.x

Krull JL, 2007 Using multilevel analyses with sibling data to increase analytic power: An illustration and simulation study. Dev. Psychol 43, 602-619. 10.1037/0012-1649.43.3.602 [PubMed: 17484574]

Lin Y, Damjanovic A, Metter EJ, Nguyen H, Truong T, Najarro K, Morris C, Longo DL, Zhan M, Ferrucci L, Hodes RJ, Weng N, 2015 Age-associated telomere attrition of lymphocytes in vivo is co-ordinated with changes in telomerase activity, composition of lymphocyte subsets and health conditions. Clin. Sci 128, 367-377. 10.1042/CS20140481 [PubMed: 25317735]

Liu Y, Sanoff HK, Cho H, Burd CE, Torrice C, Ibrahim JG, Thomas NE, Sharpless NE, 2009 Expression of p16INK4a in peripheral blood T-cells is a biomarker of human aging. Aging Cell 8, 439-448. 10.1111/j.1474-9726.2009.00489.x [PubMed: 19485966]

López-Otín C, Blasco MA, Partridge L, Serrano M, Kroemer G, 2013 The hallmarks of aging. Cell 153, 1194-1217. 10.1016/j.cell.2013.05.039 [PubMed: 23746838]

Marsland AL, Walsh C, Lockwood K, John-Henderson NA, 2017 The effects of acute psychological stress on circulating and stimulated inflammatory markers: A systematic review and meta-analysis. Brain. Behav. Immun 64, 208-219. 10.1016/j.bbi.2017.01.011 [PubMed: 28089638]

Mathur MB, Epel E, Kind S, Desai M, Parks CG, Sandler DP, Khazeni N, 2016 Perceived stress and telomere length: A systematic review, meta-analysis, and methodologic considerations for advancing the field. Brain. Behav. Immun 54, 158-169. 10.1016/j.bbi.2016.02.002 [PubMed: 26853993]

Miller GE, Chen E, 2006 Life stress and diminished expression of genes encoding glucocorticoid receptor and beta2-adrenergic receptor in children with asthma. Proc. Natl. Acad. Sci 103, 54965501. 10.1073/pnas.0506312103 [PubMed: 16567656] 
Miller GE, Rohleder N, Cole SW, 2009 NIH Public Access. Psychosom. Med 71, 57-62. 10.1097/PSY. Ob013e318190d7de.Chronic [PubMed: 19073750]

Moffitt TE, Arseneault L, Danese A, Fisher H, Mill J, Pariante C, Baucom D, Caspi A, Chen E, Miller G, Halweg K, Job AK, Heinrichs N, Haldimann BH, Grawe-Gerber M, KuperYamanaka M, Sanders M, Shalev I, Walitza S, 2013 Childhood exposure to violence and lifelong health: Clinical intervention science and stress-biology research join forces. Dev. Psychopathol 25, 1619-1634. 10.1017/S0954579413000801 [PubMed: 24342859]

O’Donovan A, Tomiyama AJ, Lin J, Puterman E, Adler NE, Kemeny M, Wolkowitz OM, Blackburn EH, Epel ES, 2012 Stress appraisals and cellular aging: A key role for anticipatory threat in the relationship between psychological stress and telomere length. Brain. Behav. Immun 26, 573-579. 10.1016/j.bbi.2012.01.007 [PubMed: 22293459]

Park M, Verhoeven JE, Cuijpers P, Reynolds CF, Penninx BWJH, 2015 Where you live may make you old: The association between perceived poor neighborhood quality and leukocyte telomere length. PLoS One 10 10.1371/journal.pone.0128460

Puterman E, Epel E, 2012 An Intricate Dance: Life Experience, Multisystem Resiliency, and Rate of Telomere Decline Throughout the Lifespan. Soc. Personal. Psychol. Compass 6, 807-825. 10.1111/j.1751-9004.2012.00465.x [PubMed: 23162608]

Puterman E, Lin J, Blackburn E, O’Donovan A, Adler N, Epel E, 2010 The power of exercise: Buffering the effect of chronic stress on telomere length. PLoS One 5 10.1371/journal.pone. 0010837

Puterman E, Lin J, Krauss J, Blackburn EH, Epel ES, 2015 Determinants of telomere attrition over 1 year in healthy older women: Stress and health behaviors matter. Mol. Psychiatry 20, 529-535. 10.1038/mp.2014.70 [PubMed: 25070535]

Ressler S, Bartkova J, Niederegger H, Bartek J, Scharffetter-Kochanek K, Jansen-Dürr P, Wlaschek M, 2006 p16INK4A is a robust in vivo biomarker of cellular aging in human skin. Aging Cell 5, 379389. 10.1111/j.1474-9726.2006.00231.x [PubMed: 16911562]

Robles TF, Carroll JE, 2011 Restorative biological processes and health. Soc. Personal. Psychol. Compass 5, 518-537. 10.1111/j.1751-9004.2011.00368.x [PubMed: 21927619]

Robles TF, Carroll JE, Bai S, Reynolds BM, Esquivel S, Repetti RL, 2016 Emotions and family interactions in childhood: Associations with leukocyte telomere length emotions, family interactions, and telomere length. Psychoneuroendocrinology 63, 343-350. 10.1016/j.psyneuen. 2015.10.018 [PubMed: 26551267]

Robles TF, Repetti RL, Reynolds BM, Chung PJ, Arevalo JMG, Cole SW, 2018 Family environments and leukocyte transcriptome indicators of a proinflammatory phenotype in children and parents. Dev. Psychopathol 30, 235-253. 10.1017/S0954579417000591 [PubMed: 28555535]

Rodier F, Campisi J, 2011 Four faces of cellular senescence. J. Cell Biol 192, 547-556. 10.1083/jcb. 201009094 [PubMed: 21321098]

Schaakxs R, Wielaard I, Verhoeven JE, Beekman ATF, Penninx BWJH, Comijs HC, 2016 Early and recent psychosocial stress and telomere length in older adults. Int. Psychogeriatrics 28, 405-413. $10.1017 / \mathrm{S} 1041610215001155$

Shalev I, 2012 Early life stress and telomere length: Investigating the connection and possible mechanisms: A critical survey of the evidence base, research methodology and basic biology. BioEssays 34, 943-952. 10.1002/bies.201200084 [PubMed: 22991129]

Shalev I, Moffitt TE, Braithwaite AW, Danese A, Fleming NI, Goldman-Mellor S, Harrington HL, Houts RM, Israel S, Poulton R, Robertson SP, Sugden K, Williams B, Caspi A, 2014 Internalizing disorders and leukocyte telomere erosion: A prospective study of depression, generalized anxiety disorder and post-Traumatic stress disorder. Mol. Psychiatry 19, 1163-1170. 10.1038/mp. 2013.183 [PubMed: 24419039]

Shalev I, Moffitt TE, Sugden K, Williams B, Houts RM, Danese A, Mill J, Arseneault L, Caspi A, 2013 Exposure to violence during childhood is associated with telomere erosion from 5 to 10 years of age: A longitudinal study. Mol. Psychiatry 18, 576-581. 10.1038/mp.2012.32 [PubMed: 22525489] 
Teyssier JR, Chauvet-Gelinier JC, Ragot S, Bonin B, 2012 Up-Regulation of leucocytes Genes Implicated in Telomere Dysfunction and Cellular Senescence Correlates with Depression and Anxiety Severity Scores. PLoS One 7 10.1371/journal.pone.0049677

Weng N, 2001 Interplay between telomere length and telomerase in human leukocyte differentiation and aging. J. Leukoc. Biol 70, 861-7. [PubMed: 11739547] 


\section{Highlights:}

- $\quad$ Greater chronic stress exposure associated with elevated p16 ${ }^{\text {INK4a }}$ gene expression.

- $\quad$ Greater perceived stress associated with increased $\mathrm{p} 16^{\mathrm{INK} 4 \mathrm{a}}$ gene expression.

- $\quad$ Greater accumulated daily stress appraisals associated with elevated p16 $6^{\text {INK4a }}$ mRNA.

- $\quad$ Psychosocial stress measures were not associated with leukocyte telomere length. 

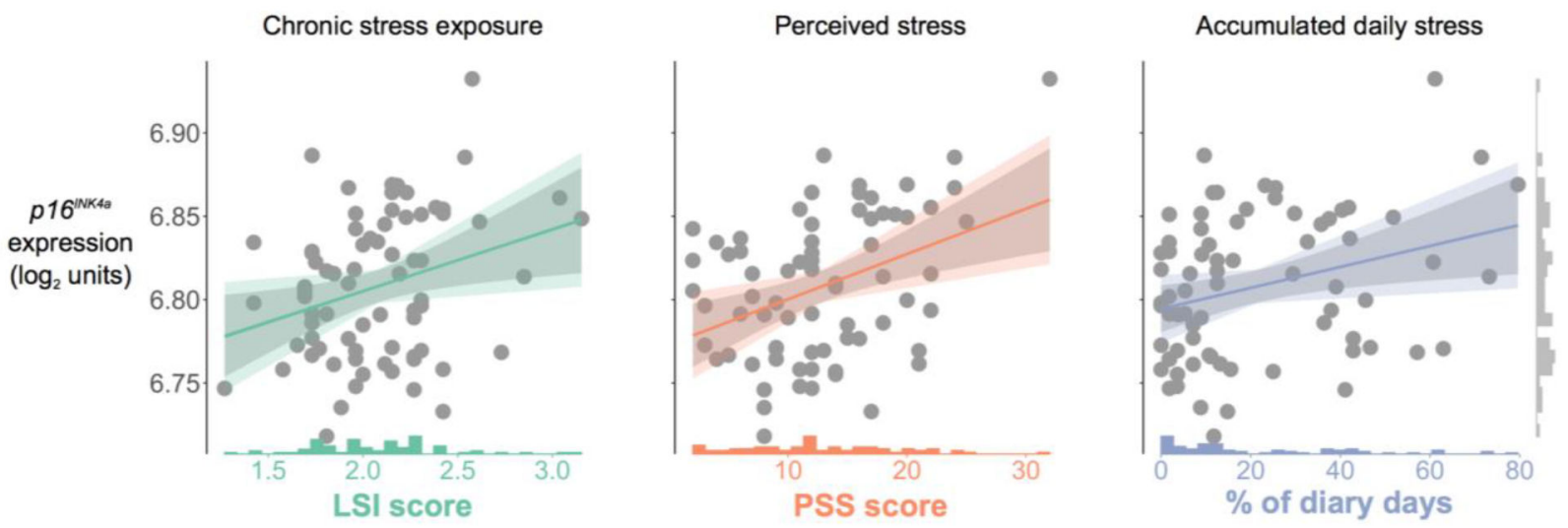

Figure 1.

Scatterplots of the associations between cellular senescence signal p16 ${ }^{\mathrm{INK} 4 \mathrm{a}}$ and chronic stress exposure (LSI, left plot in green), perceived stress (PSS, middle plot in orange), and accumulated daily stress (\% of diary days reporting "stressed" or "overwhelmed" as "mostly accurate" or "completely" accurate, right plot in blue). Histograms depicting the sample distribution of each psychosocial stress measure are shown on the x-axis. A histogram depicting the sample distribution of $p 16^{I N K 4 a}$ expression ( $\log _{2}$ units) is shown in the vertical margin on the right. Solid lines were plotted using parameter estimates from the unadjusted models in Table 3. The grey shaded bands reflect the $95 \%$ CI for the best fit regression line computed from the raw data; colored shaded bands reflect areas bounded by combinations of the upper and lower limits of the $95 \%$ CIs for both intercept and slope parameter estimates from the unadjusted models. 


\section{Table 1}

Descriptive statistics for psychosocial stress and cellular aging variables $(N=73)$.

\begin{tabular}{|c|c|c|c|}
\hline Psychosocial stress variables & $M$ & $S D$ & Range \\
\hline Chronic stress exposure (1-5) & 2.08 & 0.35 & $1.27-3.15$ \\
\hline Perceived stress $(0-40)$ & 12.83 & 6.33 & $2.00-32.00$ \\
\hline Accumulated daily stress (\%) & 21.40 & 20.86 & $0-79.63$ \\
\hline \multicolumn{4}{|l|}{ Cellular aging variables } \\
\hline Leukocyte telomere length & 1.05 & 0.30 & $0.46-1.80$ \\
\hline Cellular senescence signal $\mathrm{p} 16^{\mathrm{INK4a}}$ & 6.81 & 0.04 & $6.72-6.93$ \\
\hline
\end{tabular}

Note. For perceived stress, $N=71$, and for leukocyte telomere length, $N=69$. 
Table 2

Random effects models with psychosocial stress predicting leukocyte telomere length

\begin{tabular}{lcccccc}
\hline & \multicolumn{3}{c}{ Unadjusted models $(\mathbf{N}=\mathbf{6 9})$} & \multicolumn{3}{c}{ Adjusted models $(\boldsymbol{N}=\mathbf{6 9})$} \\
Model & $\boldsymbol{b}$ & $\boldsymbol{p}$ & $\mathbf{9 5 \%} \mathbf{C I}$ & $\boldsymbol{b}$ & $\boldsymbol{p}$ & $\mathbf{9 5 \%} \mathbf{~ C I}$ \\
\hline 1. Chronic stress exposure & -0.023 & .52 & $-0.095,0.048$ & -0.028 & .45 & $-0.103,0.046$ \\
Age & & & & -0.050 & .23 & $-0.133,0.032$ \\
Sex & & & & 0.032 & .65 & $-0.106,0.170$ \\
Body mass index & & & & 0.020 & .63 & $-0.064,0.105$ \\
Hispanic ethnicity & & & & -0.036 & .71 & $-0.225,0.154$ \\
African American race & & & & 0.081 & .46 & $-0.138,0.300$ \\
2. Perceived stress & 0.060 & .10 & $-0.011,0.131$ & 0.047 & .24 & $-0.032,0.127$ \\
Age & & & & -0.066 & .12 & $-0.150,0.018$ \\
Sex & & & & 0.019 & .79 & $-0.122,0.160$ \\
Body mass index & & & & 0.008 & .85 & $-0.077,0.093$ \\
Hispanic ethnicity & & & & -0.013 & .90 & $-0.209,0.183$ \\
African American race & & & & 0.082 & .46 & $-0.143,0.307$ \\
3. Accumulated daily stress & 0.041 & .27 & $-0.032,0.115$ & 0.057 & .14 & $-0.020,0.133$ \\
Age & & & & -0.066 & .11 & $-0.147,0.014$ \\
Sex & & & & -0.03 & .97 & $-0.145,0.140$ \\
Body mass index & & & & 0.016 & .70 & $-0.066,0.098$ \\
Hispanic ethnicity & & & & -0.025 & .79 & $-0.211,0.162$ \\
African American race & & & & 0.071 & .50 & $-0.138,0.280$ \\
\hline
\end{tabular}

Note. $\mathrm{CI}=$ confidence interval. All continuous variables are $z$-transformed. For models with perceived stress, $N=67$. 
Table 3

Random effects models with psychosocial stress predicting cellular senescence marker p16 ${ }^{\mathrm{INK} 4 \mathrm{a}}$

\begin{tabular}{lcccccc}
\hline & \multicolumn{3}{c}{ Unadjusted models $(\boldsymbol{N}=\mathbf{7 3})$} & \multicolumn{3}{c}{ Adjusted models $(\boldsymbol{N}=\mathbf{7 2})$} \\
Variables & $\boldsymbol{b}$ & $\boldsymbol{p}$ & $\mathbf{9 5 \%} \mathbf{C I}$ & $\boldsymbol{b}$ & $p$ & $\mathbf{9 5 \%} \mathbf{C I}$ \\
\hline 1. Chronic stress exposure & 0.013 & .01 & $0.003,0.023$ & 0.011 & .04 & $0.001,0.022$ \\
Age & & & & 0.006 & .29 & $-0.005,0.017$ \\
Sex & & & & 0.007 & .51 & $-0.014,0.028$ \\
Body mass index & & & & 0.003 & .56 & $-0.008,0.015$ \\
Hispanic ethnicity & & & & 0.011 & .43 & $-0.016,0.037$ \\
African American race & & & & 0.007 & .63 & $-0.021,0.035$ \\
2. Perceived stress & \multirow{2}{*}{.017} & .001 & $0.008,0.027$ & 0.020 & $<.001$ & $0.010,0.030$ \\
Age & & & & 0.008 & .11 & $-0.002,0.018$ \\
Sex & & & & -0.002 & .87 & $-0.023,0.019$ \\
Body mass index & & & & 0.003 & .57 & $-0.007,0.013$ \\
Hispanic ethnicity & & & & 0.026 & .04 & $0.001,0.051$ \\
African American race & & & & 0.000 & .98 & $-0.025,0.025$ \\
3. Accumulated daily stress & 0.013 & .01 & $0.003,0.023$ & 0.013 & .02 & $0.002,0.023$ \\
Age & & & & 0.005 & .37 & $-0.006,0.016$ \\
Sex & & & & 0.005 & .60 & $-0.015,0.026$ \\
Body mass index & & & & 0.006 & .29 & $-0.005,0.017$ \\
Hispanic ethnicity & & & & 0.011 & .43 & $-0.016,0.037$ \\
African American race & & & & 0.011 & .45 & $-0.017,0.038$ \\
\hline
\end{tabular}

Note. $\mathrm{CI}=$ confidence interval. All continuous predictor variables are $z$-transformed. For perceived stress, $N=71$ for unadjusted model and $N=70$ for adjusted model. 